\title{
Revealing shifts from mastery of knowledge to problem solving in assessments of a tertiary physics programme
}

\author{
Alan Cornell \\ Department of Physics, University of Johannesburg, Johannesburg, South Africa \\ acornell@uj.ac.za \\ https://orcid.org/0000-0003-1896-4628
}

\section{Kershree Padayachee}

Science Teaching and Learning Unit, Faculty of Science, University of the Witwatersrand, Johannesburg, South Africa

kershree.padayachee@wits.ac.za

https://orcid.org/0000-0001-7015-5962

(Received: 15 October 2020; accepted: 17 June 2021)

\section{Abstract}

There is an increasing pressure on lecturers to work with two goals. First, they need to ensure that their undergraduate students have a good grasp of the knowledge and skills of the intellectual field. In addition, they need to prepare graduates and postgraduates for careers both within and outside of academia. The problem we address in this paper is the way in which assessments may reveal a shift of focus from a mastery of knowledge to a work-focused orientation. We examine this shift through a case study of physics and the sub-discipline of theoretical physics as intellectual fields. The evidence is comprised of assessment tasks given to students at different points of their studies from first year to doctoral level. By examining and analysing the assessment tasks using concepts from Legitimation Code Theory (LCT), we demonstrate how the shifts in the assessments lead students incrementally from a pure disciplinary focus to one that enables them to pursue employment potentially both within and outside of academia. In doing so, we also highlight the usefulness of LCT as a framework for evaluating the preparation of science students for diverse workplaces.

Keywords: physics education, Legitimation Code Theory, epistemic relations, assessment

\section{Introduction}

The higher education landscape has shifted dramatically over the past 20 years. Worldwide, staff and student demographics have changed, and the very purpose of higher education is being challenged. The world of work is also currently in a state of flux, with requirements for new so-called 21st century skills and competency emerging constantly (Bao and Koenig, 
2019). The result is increasing pressure for lecturers to shift curricula that focus tightly on disciplinary knowledge and procedures and provide greater opportunities for students to develop broader cross field competencies that will equip them for a wide range of potential careers (Ashwin \& Case, 2018; Roberts, 2015).

The branching out of the academic pipeline, with graduates (especially those with higher degrees) entering workplaces that are vastly different from the academic environment in which they have been prepared has implications. These include the need for graduates to develop both in-depth and highly sophisticated understandings of the knowledge of their disciplines so that they can apply this knowledge to a broad range of contexts and fields of practice (Acker \& Haque, 2017). It may also have implications for the type of identity graduate students develop, based on their intrinsic motivations and their intended career paths. Higher education, therefore, needs to adapt in response to the shifting socio-economic pressures and requirements to enable the development of graduates with flexible dispositions that would allow for easier integration into new contexts and easier application of disciplinary knowledge in fields of practice beyond academe. However, while undoubtedly necessary, it is possible that such shifts may present challenges for the development and training of students in pure hard science disciplines such as physics and specialised subdisciplines such as theoretical physics. In this paper, we first analyse what is valued in the discipline at different stages of theoretical physics education. We then draw on the analysis to highlight the epistemological shifts that occur in the process of theoretical physicist identity development as students move from first year to $\mathrm{PhD}$ level in the discipline. Last, we discuss how these shifts incrementally develop students' abilities to create new knowledge and apply the knowledge of physics and theoretical physics in other fields over time.

\section{Progression in the learning of physics}

Physics is regarded as a discipline in which progress is attained by seeking greater levels of abstraction, such as universally applicable laws that govern natural phenomena. Terms are generally precisely defined and there are similar bodies of knowledge taught in introductory physics courses in different institutions. On these grounds, physics can be described as having a generally hierarchical knowledge structure in which there is broad consensus on precisely defined concepts and relationships between them. In fields like these, knowledgebuilding happens through the integration of foundational concepts with more abstract and universal claims (Bernstein, 1999, 2000). This means that the undergraduate physics curricula tend to follow similar topics and sequences across different settings. This curriculum format is deemed necessary to ensure that students become familiar with the foundational knowledge and procedures of the discipline.

First year physics classes generally include students registered for engineering and medical degrees, as well as those intending to major in physics or chemistry. An introductory course in physics would usually include topics relating to Newtonian mechanics, waves and optics, electromagnetism and so on. At this level, the curriculum would also include the development of thinking and reasoning skills involved in enquiry, experimentation, and 
evidence evaluation. The transition to the more specialised sub-disciplines of theoretical physics occurs in the latter years of the undergraduate programme and requires greater conceptual understanding and knowledge integration. Compared with general physics courses, specialised sub-disciplines such as theoretical physics focus on the more abstract generation of theoretical models, require more complex mathematical knowledge, and demand a higher level of logic and critical thinking. In this respect, critical thinking skills are expanded to include inference and argumentation, the ability to systematically explore a problem, formulation and testing of hypotheses, manipulation and isolation of variables, and observation and evaluation of consequences (Zimmerman, 2000). In the process of becoming increasingly specialised, experiential aspects of physics are left aside in favour of a greater emphasis on conceptual understanding and the development of particular mental models and procedural knowledge.

There is, accordingly, a gradual development of increasingly complex conceptual understanding that occurs in the education of theoretical physics students, evolving from conceptual knowledge acquisition to an understanding and comprehension of the knowledge and the specific procedures that are underpinned by these. In other words, students are gradually inducted into the discipline and the practice of knowledge production, gaining foundational knowledge and learning to think like a physicist during undergraduate studies (Conana, 2016; Conana et al., 2020; Van Heuvelen, 1991). Lecturers thus aim initially to construct disciplinary knowledge in a hierarchical manner by beginning with hands-on experiential work through laboratories and practicals that quickly become a repeated testing of invented threshold concepts (Wisker, 2018) such as Newton's laws etc., to see if these always hold up under scrutiny, as well as the constant development of students' understanding of complex representations and their uses in physics.

This repeated testing and questioning that characterises undergraduate studies is a key aspect of the physicist's identity, founded on Dewey's notion of “competent inquiry" (Dewey, 1938, cited in Towne \& Shavelson, 2002, p. 51). It can also be associated with Popper's critical rationalism amongst other scientific philosophies (Towne and Shavelson, 2002). The key point is that the scientific laws that we seek to formulate are abstract ones that must be tested constantly. In the context of theoretical physics, this is captured in the lecture series entitled "Character of Physical Law", by Feynman (1965), that explains how he saw physical laws; he suggested that a theoretical physicist attempts to write down, in the language of mathematics, a simple and beautiful explanation for nature. Feynman pointed out, however, that this is, at best, a model, one that will have only a certain regime of applicability. Physicists test the range of this model, while refining and improving it, in a search for new laws and broader or deeper understandings and applications, making this the cornerstone of physics education.

Physics education, therefore, needs to be underpinned by an appreciation of the nature of science and a solid conceptual foundation from which the skills of abstraction, critical thinking, and new knowledge production can emerge. The undergraduate physics curriculum, therefore, requires a solid conceptual foundation that includes critical thinking skills for subsequent abstraction and knowledge production. The role of the physics lecturer is, 
consequently, to facilitate access to, and engagement with, the concepts in a way that leads students to ever more complex levels of abstraction and criticality, and in the process, gradually shape a scientific identity and the "trained gaze" (Maton, 2014, p. 186) of a theoretical physicist. In this sense, a gaze is a specialised way of seeing, perceiving, and thinking in the knowledge practices of physics and has been developed through interactions, including assessment tasks that emphasise the mastery of specialist knowledge and skills.

Conana (2016) and Conana et al. (2020) have explained how a process of knowledgebuilding of specialised knowledge and skills typically occurs in first year physics lectures, and how a deliberate interplay between everyday knowledge enhances understanding of physics concepts and procedures. This approach enables students to see the application and broader relevance of concepts from the discipline, making engagement with the concepts more meaningful for students studying physics as a pre-requisite for further study in the related fields of medicine and engineering. It also triggers interest and curiosity in students who intend majoring in physics. It can be argued, however, that it is summative assessments in the curriculum that ultimately drive students' focus and determine their success, by signalling to them which knowledge mastery and graduate attributes are valued at each stage of study (Boud \& Falchikov, 2006).

In the case of physics and theoretical physics, the shifts towards increasing complex conceptual understanding, greater levels of intellectual independence, and demands for disciplinary ways of thinking and reasoning as key outcomes of the courses, should, therefore, be reflected in the demands of assessment tasks. It is, therefore, crucial to our endeavour to analyse how the physics and theoretical physics assessment demands vary to promote the students' ability to develop and then apply the knowledge of these disciplines in different ones and in work contexts. Analysing knowledge practices, like shifts in assessment tasks in an intellectual field like physics, however, requires a conceptual framework that can reveal changes in what is valued for achievement over different levels. It is for this reason that we turn now to the conceptual tools offered by the Specialization dimension of Legitimation Code Theory (LCT) (Maton, 2014).

\section{Epistemic relations and learning physics in higher education}

LCT offers a sociological approach to researching and analysing knowledge practices. It offers a multidimensional conceptual toolkit that enables "both the exploration of knowledgebuilding and the cumulative building of knowledge" allowing "knowledge practices to be seen, their organizing principles to be conceptualized, and their effects to be explored" (Maton, 2014, p. 4). This is achieved through the selective application of the different dimensions of LCT, each of which is comprised of "a series of concepts centred on capturing a set of organizing principles underlying dispositions, practices and contexts" (Maton, 2016, p. 11). The Specialization dimension provides concepts that reveal the extent to which the basis of achievement in a practice or intellectual field lies in the mastery of a body of specialised knowledge and/or the acquisition of specialised dispositions and ways of thinking 
or being. Conceptual tools from LCT have been used to analyse assessment tasks in chemistry (e.g., Blackie, 2014), student understandings in physics (e.g., Georgiou, 2016) and knowledge-building in earth sciences (e.g., Maton \& Doran, 2021). In this paper we use the strength of epistemic relations and knowledge-based insights to consider how the focus on knowledge and procedures shifts in the assessment of physics at various levels in a higher education setting.

The Specialization dimension of LCT arises from the principle that knowledge practices are oriented towards a part of the world and are enacted by actors. This principle sets up two relations: epistemic relations (ER) between the practice and its objects of study; and social relations (SR) between the practice and its subjects. Epistemic relations are defined by relations of the knowledge to its object of study (i.e., the relation between the knowledge and the part of the world or disciplinary field to which the body of knowledge is directed). In contrast, social relations are defined by relations between the knowledge practices and the subject (i.e., the relations between those making the claim to the knowledge).

When the epistemic and/or social relations are highly significant as a basis for achievement in the knowledge practice, relations are regarded as being stronger along a continuum of strengths. When the relations matter less as a basis for achievement, the relations are said to be relatively weaker. Different intellectual fields and different fields of professional practice may thus be characterised by the relative strengths or weaknesses placed on epistemic and social relations which may be indicated by + or - , respectively.

The concepts and codes of Specialization provided the language and tools to analyse the logics that underpin the development of theoretical physicists as a starting point for a deeper exploration of what is valued as the basis of achievement in this field. Moreover, in this study we focus on how cognitive demands in assessment tasks shift over time as students move from undergraduate to postgraduate physics courses. We are especially interested in what knowledge insights are developed through shifts in the epistemic relations of the knowledge practices of physics. For this reason, we focus on the epistemic plane of LCT which gives us the means to analyse how epistemic relations change strength and form in the assessments at different stages of a theoretical physicists' education, both at undergraduate and postgraduate level.

The epistemic relations of knowledge practices may be specialised according to the extent to which the field determines legitimate objects of study, and the procedures by which these objects are investigated (Maton, 2014). The epistemic plane enables deeper consideration of the object of study of one field relative to another through considerations of the relative strengths of the ontic and discursive relations. Ontic relations (OR) describe the extent to which the object of study in the field is bound to the field, i.e., the what of its knowledge practices. The ontic relations, therefore, reflect the strengths of relations between knowledge practices within the intellectual field and their demarcated object/s of study (Maton, 2014). The term, discursive relations (DR), however, refers to the extent to which there are clear and uncontested procedures that determine how those object/s are studied. Discursive relations therefore, set up relative strengths between knowledge practices associated with a particular 
intellectual field (in this study, physics) and procedures used to investigate problems in other knowledge practices (Maton, 2014). In short, discursive relations consider the how of knowledge practices.

Maton (2014) explained that a field's ontic and discursive relations can also be combined to illustrate the continuum of strengths of relations on the epistemic plane, resulting in four analytically distinct quadrants representing four insights of epistemic codes, viz., purist, doctrinal, knower/no and situational (Figure 1).

- Knowledge practices dominated by purist insights are generated by fields that "strongly bound and control both legitimate objects of study and the legitimate approaches" used to study them (Maton, 2014, p. 176). Such fields in which the object of study and approaches are strongly controlled by the field, are said to be characterised by strong ontic fidelity and procedural purism.

- In comparison, knowledge practices characterised by doctrinal insights (OR-, DR+) are generated by fields in which the object of study is less determined by the field (weaker ontic fidelity) but specialised procedures are of greater significance for achievement in the field (stronger discursive relations).

- Situational insights (OR+, DR-), however, develop in knowledge practices where the object of study is controlled by the field but there is greater potential for application of multiple approaches or procedures to address a particular issue or problem.

- Knower insights or no knowledge-based insights, in contrast, are generated in practices in which neither the objects of study nor the procedures used to study them are dictated by the field. These insights are characterised by generally weaker ontic and discursive relations.

Figure 1

The epistemic plane of LCT, showing four codes that form the basis of knowledge-based insights (Maton, 2014)

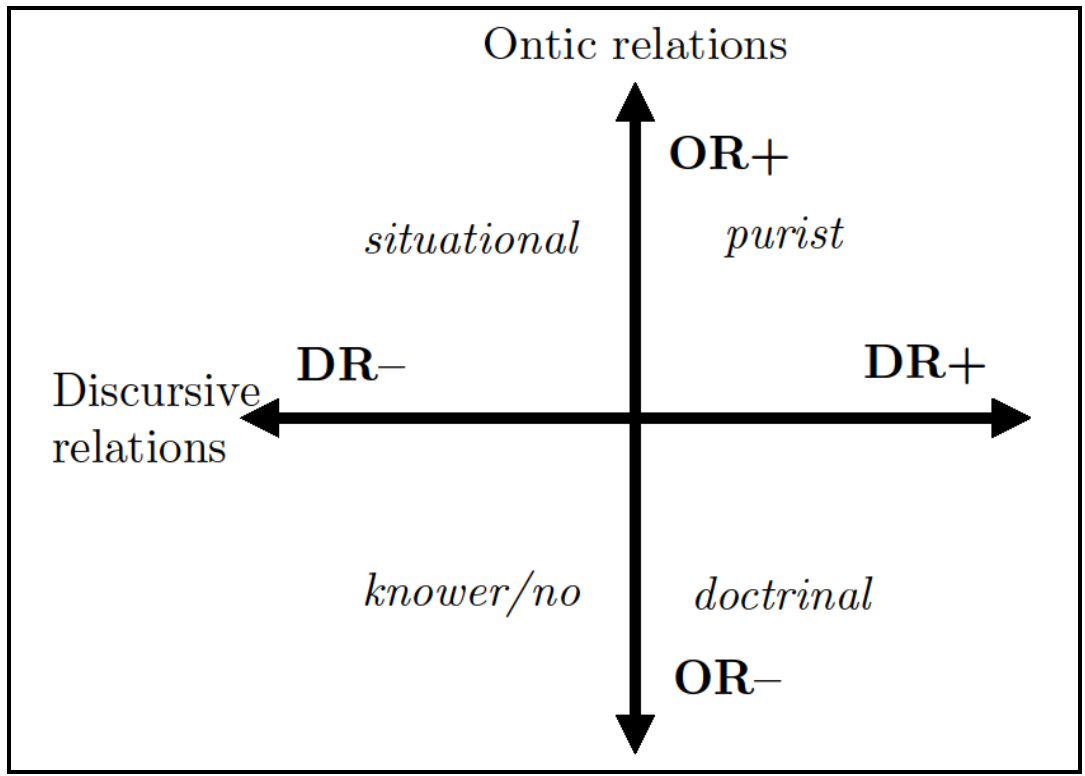


The epistemic plane thus provided a useful analytical framework for analysing the assessments in order to reveal the knowledge practices that are foregrounded in the education of theoretical physicists, and the extent to which the programme prepares students for diverse workplaces.

\section{Methodology}

In this paper, we offer a qualitative analysis of assessment tasks designed for undergraduate physics courses as well as assessments from theoretical physics Honours courses, Masters, and $\mathrm{PhD}$ projects in theoretical physics. These were designed by the first author, a theoretical physicist specialising in high energy particle physics and gravitational physics at an urban university in South Africa. Supporting data was also derived from a closely focussed conversation between the first author and the second, an educational developer based in the Faculty of Science of another urban university in South Africa, in which the first author reflected on the nature of the assessments and the reasons for the assessment strategies adopted at different levels of study. The assessment artefacts and the transcript of his reflection on the types of questions were first analysed using a soft eyes approach (superficial examination) to determine the dominant Specialization code. This was followed by a more rigorous confirmation of the dominance of the Specialization code using a translation device that was developed to identify and distinguish between epistemic and social relations and the relative strengths of these.

Having determined that epistemic relations were emphasised much more strongly than social relations in our data, a second translation device (Table 1) was created and applied to evaluate the relative strengths of the ontic and discursive relations.

Table 1

The translation device used to evaluate the relative strengths of the ontic and discursive relations in summative assessments and in the transcript of the lecturer interview

\begin{tabular}{|c|c|c|c|}
\hline \multicolumn{3}{|c|}{ ONTIC RELATIONS (OR) } & \multirow[b]{2}{*}{ Example } \\
\hline $\begin{array}{l}\text { Theoretical } \\
\text { concept }\end{array}$ & Code & Indicators & \\
\hline \multirow[t]{3}{*}{ Knowledge } & $\begin{array}{l}\text { OR++ } \\
\text { (very strong } \\
\text { ontic relations) }\end{array}$ & $\begin{array}{l}\text { The focus is on what is being studied } \\
\text { (disciplinary knowledge). There is a } \\
\text { notion of right knowledge. The } \\
\text { objects of study are tightly defined, } \\
\text { strongly bounded, and very strongly } \\
\text { classified. }\end{array}$ & $\begin{array}{l}\text { how matter moves and interacts in } \\
\text { an idealised way }\end{array}$ \\
\hline & $\begin{array}{l}\text { OR+ } \\
\text { (stronger ontic } \\
\text { relations) }\end{array}$ & $\begin{array}{l}\text { The emphasis is on the understanding } \\
\text { of physics-based concepts and } \\
\text { principles in settings beyond physics. }\end{array}$ & $\begin{array}{l}\text { how matter moves and interacts in } \\
\text { everyday settings }\end{array}$ \\
\hline & $\begin{array}{l}\text { OR- } \\
\text { (weaker ontic } \\
\text { relations) }\end{array}$ & $\begin{array}{l}\text { There is less emphasis on } \\
\text { disciplinary knowledge with } \\
\text { concepts and contexts beyond } \\
\text { physics. }\end{array}$ & $\begin{array}{l}\text { the interactions and relationships of } \\
\text { objects beyond the focus of physics }\end{array}$ \\
\hline
\end{tabular}




\begin{tabular}{|c|c|c|c|}
\hline \multicolumn{3}{|c|}{ DISCURSIVE RELATIONS (DR) } & \\
\hline \multirow[t]{3}{*}{ Procedures } & $\begin{array}{l}\text { DR++ } \\
\text { (very strong } \\
\text { discursive } \\
\text { relations) }\end{array}$ & $\begin{array}{l}\text { There are few connections to, and/or } \\
\text { integration of, other knowledges. }\end{array}$ & $\begin{array}{l}\text { scientific method, testing } \\
\text { hypothesis through empirical } \\
\text { observation and controlled } \\
\text { experimentation }\end{array}$ \\
\hline & $\begin{array}{l}\text { DR+ } \\
\text { (stronger } \\
\text { discursive } \\
\text { relations) }\end{array}$ & $\begin{array}{l}\text { The emphasis is on integration and } \\
\text { application of and procedures from } \\
\text { other subdisciplines within the same } \\
\text { field or closely related scientific } \\
\text { fields. }\end{array}$ & $\begin{array}{l}\text { using differential equation to model } \\
\text { a system, e.g., circuits }\end{array}$ \\
\hline & $\begin{array}{l}\text { DR- } \\
\text { (weaker } \\
\text { discursive } \\
\text { relations) }\end{array}$ & $\begin{array}{l}\text { There is possible application of a } \\
\text { wide range of procedures from } \\
\text { various disciplines (beyond closely } \\
\text { related fields). }\end{array}$ & $\begin{array}{l}\text { applications that lie beyond } \\
\text { experimental methods, analysis of } \\
\text { observed or measured variables }\end{array}$ \\
\hline
\end{tabular}

A limitation of the study presented here is that we focus on the analysis of questions from one summative assessment in each of the undergraduate and Honours years of study. The choice of assessment question presented in the findings that follow were chosen by the lecturer who set them as being exemplars of the kinds of questions typically posed to students at each level.

\section{Findings}

The first phase of the analysis using both the soft eyes approach and the application of the translation device to distinguish the types of questions and the relative strengths of the social and epistemic relations in the assessments, confirmed the existence of stronger epistemic relations and the dominance of the knowledge code in all the assessments at all levels. No questions required explicit demonstration of particular knower attributes, with the focus lying, instead, on the demonstration of conceptual and procedural understanding. This was expected and is supported by the literature on physics curricula (Bernstein, 1999) and studies on the teaching of undergraduate physics (Conana et al., 2020). The in-depth conversation between the authors also revealed an emphasis on concepts and procedures assessed at different levels and the reasons for the incremental shifts, and there was little mention of knower dispositions. Social relations in the data were consequently much weaker overall compared with the strength of the epistemic relations.

The confirmation of stronger epistemic relations and weaker social relations in all the assessment tasks enabled us to assign what we call a knowledge code to the tasks in the initial analysis of the assessments. This raised the question about what knowledge-based insights were developed through the assessment tasks. This allowed for progression to Phase 2 that involved the examination of the topography of the knowledge practices found in the assessments for different years of study, on the epistemic plane. This examination revealed the dominance of purist insights $(\mathrm{OR}+, \mathrm{DR}+)$ at all levels except $\mathrm{PhD}$, where students may either choose to remain within the field of theoretical physics or opt for projects requiring the application of disciplinary knowledge in different intellectual fields, the latter resulting in a shift into a situational insight (Figure 2). 
Figure 2

A visual representation of the shifts in the strengths of ontic and social relations in the epistemic plane (Maton, 2014), evidenced in final summative assessments and postgraduate projects, as well as the lecturer's reflections on what was foregrounded in these assessments.

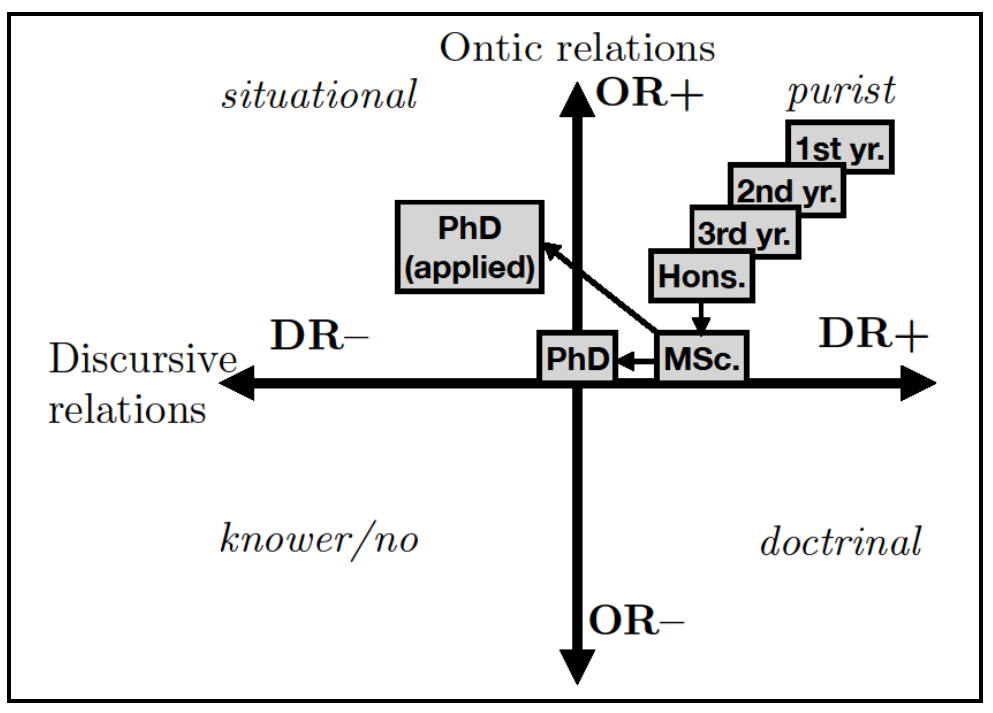

The shifts illustrated in Figure 2 can best be exemplified in the following excerpts from the data, where, as highlighted in Table 1, at first-year level problems are highly idealised and focused on simple problems involving one idea. Example 1 illustrates this type of problem, in the form of a multiple-choice question.

Example 1

\begin{tabular}{|llll|}
\hline $3685 \mathrm{~g}+66.8 \mathrm{~kg}=$ & & \\
A) $7.05 \times 10^{9} \mathrm{mg}$ & B) $7.05 \times 10^{4} \mathrm{mg}$ & C) $7.05 \times 10^{7} \mathrm{mg}$ & D) $7.05 \times 10^{6} \mathrm{mg}$ \\
E) $7.05 \times 10^{5} \mathrm{mg}$ & & & \\
\hline
\end{tabular}

In this example and all others that follow, the basis of achievement lies entirely in the mastery of units of measurement (stronger epistemic relation) and does not require any specialised disposition or attribute of the students to succeed (very weak social relation). The emphasis is on the recognition of the differences in the units of mass and the student's ability to convert to the same unit and only then add the values. The focus of knowledge is clearly demarcated, and the four options of a possible answer show that students must convert both masses to milligrams. In addition, students are required to know how to use the mathematics notion of the power of ten. The knowledge focus of the question thus relies on both a mastery of knowledge from physics and knowledge from mathematics (as mentioned by Feynman (1965)), and reiterated by the first author in the focussed conversation with the second.

Mathematics is recognised as the language of physics . . . the sub-discipline of theoretical physics is always focussed on a mathematical model building and testing of physics.

The example above also highlights that the procedures required to answer this question are specified and strongly bounded and therefore the discursive relations are strong (DR++). 
Other questions in the first-year assessment papers similarly focused on one specific concept or procedure at a time, with a very specific right answer expected, as shown in example 2.

Example 2

In an inelastic collision between two objects:

A) the kinetic energy of the system is conserved.

B) the momentum of each object is conserved.

C) both the momentum and the kinetic energy of the system are conserved.

D) the momentum of the system is conserved but the kinetic energy of the system is not conserved.

E) the momentum of the system is not conserved.

A question like this exemplifies the statement by the first author that at first year level, "Memorisation is probably enough to pass." The first-year assessment questions thus tend to be characterised by very strong ontic relations (i.e., high ontic fidelity) as well as very strong discursive relations (i.e., procedural purism), clustering tightly on the top right-hand corner of the purist quadrant of Figure 2.

As students progress through subsequent years of study, the data shows that the assessment questions become more realistic and can be applied in wider and wider contexts in which discussion and conceptual understanding is tested more. For example, at the second year of study, a student may be asked the question shown in part b of Example 3.

Example 3

(a) Show that the wave function

$\psi(\mathrm{x})=A \mathrm{e}^{\frac{\mathrm{m \omega} \mathrm{x}^{2}}{2 \hbar}}$

solves the time-independent Schrodinger equation for a harmonic oscillator potential

$V(\mathrm{x})=\frac{1}{2} m \omega^{2} \mathrm{x}^{2}$

and find the corresponding energy.

(b) The allowed energies of the harmonic oscillator are

$$
\mathrm{E}_{\mathrm{n}}=\left(\mathrm{n}+\frac{1}{2}\right) \hbar \omega, \quad \mathrm{n}=0,1,2, \ldots
$$

Explain why the energy you found in the first part of the question (a), isn't among the allowed energies.

Example 3 would require explaining why, among the allowed energies, a particular result is not physically acceptable. Questions of this nature require demonstrating an understanding of the application of the theory to a physical, though still quite abstract, situation.

Progressing further along the qualification, students choosing to major in physics are likely to encounter fewer questions based on single concepts and procedures, with questions shifting towards a wider application of concepts and procedures and increasingly, including questions requiring problem solving, formulating inferences, and making deductions, as shown in Example 4 below. 
Example 4

1. A particle of mass $m$ coming from the left moves through the downward step potential $V(x)$ shown in Figure 1 , where $V_{0}$ is positive. Describe the classical behaviour of this particle and calculate its speed before and after the step.

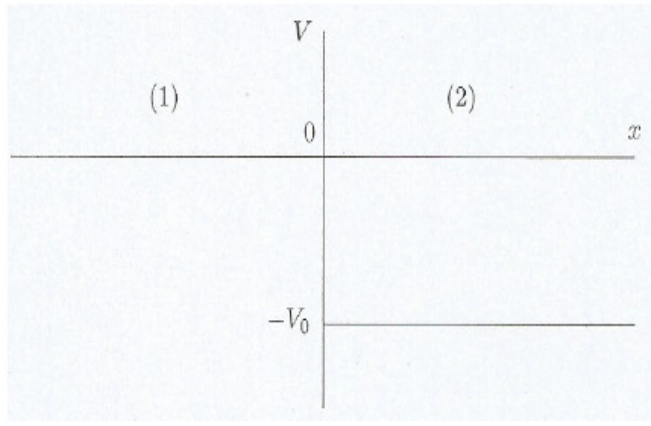

Figure 1: The downward step potential.

2. Solve the stationary Schrödinger equation with this potential for an energy $E>0$ by introducing wave numbers $k_{1}$ and $k_{2}$ as suited to domains (1) and (2).

3. Deduce the general form of the standing wave function $\psi(x)$ of a free state describing a particle coming from the left.

4. Calculate the probability currents for $x<0$ and $x>0$. Comment.

5. Deduce the reflection and transmission probabilities and compare to the classical case.

6. Plot these probabilities as a function of $E$.

Here students are required to compare quantum and classical situations, and then to discuss and deduce behaviour from this. This is particularly evident in part 5 (i.e., Deduce the reflection and transmission probabilities and compare to the classical ones). The ontic and discursive relations are, therefore, both slightly weakened compared to first-year questions, but overall, the purist code still dominates at this level of study.

At the Honours level, there is a further weakening of the ontic and discursive relations in the summative assessment questions. Example 5, for instance, requires students to apply the techniques and tools of particle physics to a condensed matter system, a topic lying outside the usual scope of such a course. As explained by the first author, with an example like this "students would not have seen principles of particle physics being applied to a condensed matter system." A question of this sort presents an opportunity for students to apply the conceptual knowledge gained in the course in a sight-unseen way, to a different field, and "any notions of compartmentalised knowledge are going out the window. Students need to draw from many previous concepts without explicit prompting." 


\section{Example 5}

Consider a scalar QED with Higgs phenomena system using the Lagrangian

$$
\mathcal{L}=\left(\mathcal{D}_{\mu} \phi\right)^{\dagger}\left(\mathcal{D}^{\mu} \phi\right)+\frac{\mu^{2}}{2} \phi^{\dagger} \phi-\lambda\left(\phi^{\dagger} \phi\right)^{2}-\frac{1}{4} F_{\mu \nu} F^{\mu \nu}
$$

with $\mathcal{D}_{\mu} \phi=\left(\partial_{\mu}-i e A_{\mu}\right) \phi$ and $F_{\mu \nu}=\partial_{\mu} A_{\nu}-\partial_{\nu} A_{\mu}$. Consider the static case where $\partial^{0} \phi=\partial^{0} \mathbf{A}=0$ and $A_{0}=0$. Recall that $\epsilon^{i j k} B^{k}=-F^{i j}$ and $E^{i}=-F^{0 i}$ in units where $c=1$.

a) Show that the equation of motion for $\mathbf{A}$ is of the form

$$
\nabla \times \mathbf{B}=\mathbf{J} \text { with } \mathbf{J}=i e\left[\phi^{\dagger}(\nabla-i e \mathbf{A}) \phi-(\nabla+i e \mathbf{A}) \phi^{\dagger} \phi\right] .
$$

b) Show that with spontaneous symmetry breaking, in the classical approximation $\phi=v=$ $\sqrt{\mu^{2} / \lambda}$, the current $\mathbf{J}$ is of the form

$$
\mathbf{J}=e^{2} v^{2} \mathbf{A} \quad \text { (the London equation) }
$$

and thus $\nabla^{2} \mathbf{B}=e^{2} v^{2} \mathbf{B}$, the Meissner effect (what solution to $\mathbf{B}$ does this imply, and discuss $)$. Recall that $\nabla \times(\nabla \phi)=0, \nabla \cdot(\nabla \times \mathbf{D})=0, \nabla^{2} \psi=\nabla \cdot(\nabla \psi)$ and $\nabla \times(\nabla \times \mathbf{D})=$ $\nabla(\nabla \cdot \mathbf{D})-\nabla^{2} \mathbf{D}$

c) The resistivity $\rho$ for the system is defined by

$$
\mathbf{E}=\rho \mathbf{J} .
$$

Show that, in this case of spontaneous symmetry breaking, $\rho=0$, and we have superconductivity.

Example 5 illustrates that, in Honours, the problems used in assessments require students to draw on multiple concepts and procedures from one field and to apply these potentially in a neighbouring or related field. The ontic and discursive relations are thus substantially weaker than in undergraduate assessments.

The progressive weakening of ontic and discursive relations is further evidenced in the types of Master's and PhD projects supervised by the first author. A Master's level dissertation, for example, has the student "studying the quasinormal modes of black holes using artificial neural networks." Such a study requires the integration of concepts and procedures from computer science and data analysis with advanced ideas from gravitational physics, demonstrating the weakening of ontic and discursive relations. Nevertheless, the guiding principles are based in physics and mathematics, hence the overall insight remains purist.

At $\mathrm{PhD}$ level, the progressive widening of the scope of application is advanced further to situations in which problems are now completely real world, using concepts and procedures taught in physics but applied elsewhere or in multidisciplinary ways. This is exemplified in the comment by the first author that "a good physicist should be able to solve a problem six different ways." The expectation is that the PhD student should be able to respond in seminars to questions posed by experts from different disciplines by drawing on a broad range of concepts and procedures gained in previous years of undergraduate and graduate study. Such expectations of PhD students to apply knowledge creatively and innovatively to a range of problems in different fields is seen in the example of a $\mathrm{PhD}$ graduate under the first author's supervision who completed a $\mathrm{PhD}$ on black hole physics and subsequently used the machine learning techniques learned during the $\mathrm{PhD}$ work to produce, in collaboration with medical specialists, a cardiology study that was a cross-disciplinary research article accepted 
for publication that resulted in employment in industry. This example of a $\mathrm{PhD}$ highlights two important points: 1) the weakening of discursive relations towards procedural relativism, to the extent that there is now a shift towards a situational insight, and 2) the value placed on problem solving and critical and creative thought as core outcomes for a theoretical physicist graduate at $\mathrm{PhD}$ level.

\section{Discussion}

The examples from assessments cited above, together with Figure 2, demonstrate that the knowledge-building process in physics begins with a strongly classified first year curriculum with high ontic fidelity and procedural purism to ensure that students gain the requisite conceptual foundation needed for subsequent abstraction and knowledge production. As students demonstrate a certain degree of mastery of these foundational concepts, they are able to progress into the more specialised sub-disciplines of physics such as theoretical physics, where a different type of mastery, viz., application and conceptual integration, is valued as the basis of achievement (see Figure 2). Further study develops the students' abilities to integrate and apply concepts in increasingly complex ways, in ever wider contexts, and to develop gradually the skills of enquiry required of all scientists. There is, hence, a gradual process unfolding during the different levels of study in which students are exposed to both the depth and breadth of the discipline over time. It is also in keeping with the notion of inducting students into the discipline through internalisation of foundational knowledge and having them learn gradually to think like a physicist (Quan, 2017; Van Heuvelen, 1991).

This study also demonstrates, through the exploration of the relative strengths of ontic and discursive relations foregrounded in the assessments, how they are constructively aligned with the intended outcomes of the curriculum (Biggs \& Tang, 2015). The findings show that the curriculum structure underpinning the learning journey to becoming a professional theoretical physicist is one that is grounded in mastery of the concepts and procedures of physics and the closely related intellectual field of mathematics. We suggest that it would be worthwhile for this incremental approach to knowledge-building (and the intrinsic connection with mathematics) to be explained to students so that they are able to envisage the learning journey ahead of them and engage accordingly.

The findings also highlighted the embedded expectation that physics graduates should, in the course of their undergraduate and graduate studies, develop the ability and skills to think critically (i.e., they should concurrently develop the skills to systematically explore a problem, formulate and test hypotheses, manipulate and isolate variables, and observe and evaluate consequences (Bao and Koenig, 2019). It is these skills that enable graduates to transition into fields of practice outside of academia (Wang, 2018). Interestingly, the assessments and the interview data suggest a view of critical thinking as a set of skills that develops as a result of engagement with disciplinary concepts and procedures in increasingly complex ways (aligning with the views of Bao and Koening (2019) and Zimmerman (2000)), rather than the possibility of critical thinking as an innate ability or knower attribute. We note this as a potential avenue for further exploration in the next phase of the study that will seek 
to both deepen our understanding of assessment in relation to knowledge-building in physics and related science disciplines.

The analysis of the assessments in this case study using the epistemic plane and knowledge insights of LCT also enabled us to confirm that critical thinking and cross-field application of disciplinary knowledge is indeed incrementally developed in physics and theoretical physics courses and programmes. However, the analysis also revealed that application and cross field integration of disciplinary knowledge is only explicitly emphasised and addressed from the second year of study, and foregrounded only in the higher degrees. The analysis, therefore, also revealed aspects of the assessments that could potentially be improved by greater clarity and clearer communication of intended outcomes. Making the underpinning rules of the game more visible and explicit to students at every level of study could lead to enhanced learning and improved student performance, especially for "cue sensitive" students (Gibbs, 2010, p. 2) who may strategically direct their study efforts based on perceived signals of value in assessment.

\section{Conclusion}

This study, conducted using LCT, enabled us to examine the underpinning logics of the assessments in physics and theoretical physics, thereby allowing us to reveal the extent to which the undergraduate and postgraduate curricula are aligned for the preparation of theoretical physics students for diverse workplaces. The examination of ontic and discursive relations enabled us to identify and reveal the underpinning logics of the summative assessments, and to thereby demonstrate how the assessments shift students from a pure disciplinary focus to one that elicits potential for employment both within and outside of academia. The findings also showed that while students exiting with the apex qualification of a $\mathrm{PhD}$ should be able to apply the disciplinary knowledge to solve a wide range of problems in unrelated fields, students exiting with the base qualification of the Bachelor's degree may not be as well equipped to apply their knowledge in unrelated contexts. This has important implications for students who should be advised during the course of the undergraduate qualification of the potential limitations of exiting at the level of the Bachelor's degree. Even so, this study demonstrates that graduates who do exit at this level will have developed the capacity to think critically.

Finally, we note that while limited in scope and the extent of generalisability, this case study highlights the potential value of the concepts and tools of LCT to reveal the extent to which assessments are constructively aligned to achieve mastery of knowledge and responsiveness of curricula to the needs of employers and society.

\section{Acknowledgements}

We are grateful to Lee Rusznyak (Wits LCT Hub, University of the Witwatersrand, Johannesburg) for her guidance in developing this paper. 


\section{References}

Acker, S., \& Haque, E. (2017). Left out in the academic field: Doctoral graduates deal with a decade of disappearing jobs. Canadian Journal of Higher Education/Revue Canadienne d'enseignement supérieur, 47(3), 101-119.

Ashwin, P., \& Case, J. M. (2018). Introduction. In P. Ashwin \& J. M. Case (Eds), Higher Education Pathways: South African undergraduate education and the public good (pp. 3-9). African Minds.

Bao, L., \& Koenig, K. (2019). Physics education research for 21 st century learning. Disciplinary and Interdisciplinary Science Education Research, 1(1), 1-12.

Bernstein, B. (1999). Vertical and horizontal discourse: An essay. British Journal of Sociology and Education, 20, 157-173.

Bernstein, B. (2000). Pedagogy, symbolic control, and identity: Theory, research, critique (Vol. 5). Rowman \& Littlefield.

Blackie, M. A. 2014. Creating semantic waves: Using Legitimation Code Theory as a tool to aid the teaching of chemistry. Chemistry Education Research and Practice, 15(4), 462-469. https://doi.org/10.1039/C4RP00147H

Biggs, J., \& Tang, C. (2015). Constructive alignment: An outcomes-based approach to teaching anatomy. In L. K. Chan, and W. Pawlina (Eds), Teaching anatomy (pp. 3138). Springer.

Boud, D., \& Falchikov, N. (2006). Aligning assessment with long-term learning. Assessment \& Evaluation in Higher Education, 31(4), 399-413.

Conana, C. H. 2016. Using semantic profiling to characterize pedagogical practices and student learning: A case study of two introductory physics courses (Unpublished doctoral dissertation). University of the Western Cape, Cape Town, RSA.

Conana, H., Marshall, D., \& Case, J. (2020). A semantics analysis of first-year physics teaching: Developing students' use of representations in problem-solving. In C. Winberg, S. McKenna \& K. Wilmot (Eds.), Building Knowledge in Higher Education (pp. 162-179). Routledge.

Feynman, R. P. (1965). The Character of Physical Law. Modern Library. ISBN 978-0-67960127-2.

Georgiou, H. (2016). Putting physics knowledge in the hot seat: The semantics of student understandings of thermodynamics. In K. Maton, S. Hood, \& S. Shay (Eds.), Knowledge-building: Educational studies in Legitimation Code Theory (pp. 176192). Routledge. 
Gibbs, G. (2010). Using assessment to support student learning. Leeds Met. Press.

Maton, K. (2014). Knowledge and knowers: Towards a realist sociology of education. Routledge.

Maton, K. (2016). Legitimation Code Theory: Building knowledge about knowledgebuilding. In K. Maton, S. Hood \& S. Shay (Eds.), Knowledge-building: Educational studies in Legitimation Code Theory (pp. 1-24). Routledge.

Maton, K., \& Doran, Y. J. (2021). Constellating science: How relations among ideas help build knowledge. In K. Maton, J. R. Martin \& Y. J. Doran, Y. J. (Eds.), Teaching science: Knowledge, language, pedagogy (pp. 49-75). Routledge.

Quan, G. (2017). Becoming a physicist: How identities and practices shape physics trajectories (Unpublished doctoral dissertation). University of Maryland, College Park, MD.

Roberts, P. (2015). Higher education curriculum orientations and the implications for institutional curriculum change. Teaching in Higher Education, 20(5), 542-555.

Towne, L., \& Shavelson, R. J. (2002). Scientific research in education. National Academy Press Publications Sales Office.

Van Heuvelen, A. (1991). Learning to think like a physicist: A review of research-based instructional strategies. American Journal of Physics, 59(10), 891-897.

Wang, C. (2018). Scientific culture and the construction of a world leader in science and technology. Cultures of Science, 1(1), 1-13.

Wisker, G. (2018). Different journeys: Supervisor perspectives on disciplinary conceptual threshold crossings in doctoral learning. Critical Studies in Teaching and Learning, 6(2), 1-20

Zimmerman, C. (2000). The development of scientific reasoning skills. Developmental Review, 20(1), 99-149. 